\title{
Predicting feed intake and feed efficiency in lactating dairy cows using digesta marker techniques
}

\author{
A. Guinguina ${ }^{1}$, S. Ahvenjärvi' ${ }^{2}$ E. Prestløkken ${ }^{3}$, P. Lund ${ }^{4}$ and P. Huhtanen ${ }^{1 \dagger}$ \\ ${ }^{1}$ Department of Agricultural Research for Northern Sweden, Swedish University of Agricultural Sciences, SE-901 83 Umeå, Sweden; ${ }^{2}$ Natural Resources Institute \\ Finland (Luke), Milk Production, 31600 Jokioinen, Finland; ${ }^{3}$ Department of Animal and Aquacultural Sciences, Norwegian University of Life Sciences, PO Box 5003, \\ 1432 Ås, Norway; ${ }^{4}$ Department of Animal Science, Aarhus University, AU Foulum, P.O. Box 50, 8830 Tjele, Denmark
}

(Received 20 March 2018; Accepted 21 January 2019; First published online 26 February 2019)

Direct measurement of individual animal dry matter intake (DMI) remains a fundamental challenge to assessing dairy feed efficiency (FE). Digesta marker, is currently the most used indirect technique for estimating DMI in production animals. In this meta-analysis we evaluated the performance of marker-based estimates against direct or observed measurements and developed equations for the prediction of FE (g energy-corrected milk (ECM)/kg DMI). Data were taken from 29 change-over studies consisting of 416 cow-within period observations. Most studies used more than one digesta marker. So, for each observed measurement of DMI, faecal dry matter output (FDMO) and apparent total tract dry matter digestibility (DMD), there was one or more corresponding marker estimate. There were 924, 409 and 846 observations for estimated FDMO (eFDMO), estimated apparent total tract DMD (eDMD) and estimated DMI (eDMI), respectively. The experimental diets were based mainly on grass silage, with soya bean or rapeseed meal as protein supplements and cereal grains or by-products as energy supplements. Across all diets, average forage to concentrate ratio on a dry matter (DM) basis was 59 : 41. Variance component and repeatability estimates of observed and marker estimations were determined using random factors in mixed procedures of SAS. Between-cow CV in observed FDMO, DMD and DMI was, 10.3, 1.69 and 8.04, respectively. Overall, the repeatability estimates of observed variables were greater than their corresponding marker-based estimates of repeatability. Regression of observed measurements on marker-based estimates gave good relationships $\left(\mathrm{R}^{2}=0.87,0.68,0.74\right.$ and 0.74 , relative prediction error $=10.9 \%, 6.5 \%, 15.4 \%$ and $18.7 \%$ for FDMO, DMD, DMI and FE predictions, respectively). Despite this, the mean and slope biases were statistically significant $(\mathrm{P}<0.001)$ for all regressions. More than half of the errors in all regressions were due to mean and slope biases $(52.4 \% 87.4 \%$, $82.9 \%$ and $85.8 \%$ for FDMO, DMD, DMI and FE, respectively), whereas the contributions of random errors were small. Based on residual variance, the best model for predicting FE developed from the dataset was $F E(g E C M / k g D M I)=1179( \pm 54.1)+38.2$ $( \pm 2.05) \times E C M(\mathrm{~kg} /$ day $)-0.64( \pm 0.051) \times B W(\mathrm{~kg})-75.6( \pm 4.39) \times$ eFDMO (kg/day). Although eDMD was positively related to FE, it only showed a tendency to reduce the residual variance. Despite inaccuracy in marker procedures, eFDMO from external markers provided a reliable determination for FE measurement. However, DMD estimated by internal markers did not improve prediction of $F E$, probably reflecting small variability.

Keywords: bias, digestibility, faecal output, regression, variance component

\section{Implications}

The main obstacle to assessing dairy feed efficiency $(\mathrm{FE})$ is an accurate individual animal feed intake measurement which direct recording is laborious and expensive. Therefore, indirect methods using digesta markers to estimate intake have been developed. In this study, we used a metaanalytical approach to develop models that could be used to predict feed intake and FE by means of markers. Overall, markers were not accurate in predicting dry matter intake

${ }^{\dagger}$ E-mail: pekka.huhtanen@slu.se
(DMI). However, faecal dry matter output (FDMO) estimated by external markers can improve prediction of FE thereby eliminating the added burden of measuring intake directly.

\section{Introduction}

Feed efficiency is not a new concept. Although it gained popularity in the 1970s (Hooven et al., 1972), it is only in recent years research into this area has appeared consistently in the scientific literature. This is mainly due to the increased pressure facing the dairy industry to maintain profitability in 
an era of increasing feed costs and to reduce greenhouse gas production and nutrient losses to the environment. Feed efficiency has become a more common standard for monitoring the economic viability of milk production and it is already a primary marker for genetic improvement in dairy cattle breeding programs (Vallimont et al., 2011; Pryce et al., 2015; Tempelman et al., 2015). There are numerous definitions of $\mathrm{FE}$, among which the most relevant definition for dairy production systems is still unclear (see review by Connor, 2015).

Irrespective of definition, the greatest obstacle to assessing FE is the measurement of individual animal feed intakes. Feed intake is simply and directly measured as the difference between the feed offered and that which remains uneaten or by the use of automated feed monitoring systems. While direct measurements may be quite accurate (Coleman, 2005), their use in dairy cattle generally has been limited to smaller research herds due to the high cost of measurements (Connor, 2015).

Moore (1996) suggested the marker technique as suitable for indirect estimates of individual animal intake by dividing FDMO by the indigestibility of the feed. Faecal output is estimated from an external marker while an internal marker (naturally occurring in feedstuffs) is used to estimate dry matter digestibility (DMD).

Several markers have been evaluated through the years in the search for a suitable marker (Huhtanen et al., 1994; Ferret et al., 1999) but a marker that satisfies all the requirements of the ideal marker (see review by Sales and Janssens, 2003), is yet to be established. Furthermore, simple, low cost but accurate and precise analytical techniques are required. The marker technique has been criticised for much preparation work (especially external markers) and practical inadequacies involved. As such, it has received little or no application in large herds. However, under practical conditions, they can produce important data for the advancement of research.

Therefore, the objective of the present study was to evaluate the performance of marker estimates against observed data using a large dataset from physiological digestion studies with a meta-analytical approach. Furthermore, equations were developed to assess the usefulness of marker estimates in predicting FE. A prediction equation for FE would curtail the added burden of measuring feed intake of individual cows.

\section{Material and methods}

\section{Experimental data}

The dataset comprised 416 individual cow-within period observations (after removing missing data) originating from 29 digestibility trials conducted in Denmark (5), Finland (18) and Norway (6) (Supplementary Table S1 and Supplementary Material S1). All trials were conducted as either Latin square or cyclic change-over designs using rumencannulated cows. The mean forage to concentrate ratio of the diets was $59: 41$ on a dry matter (DM) basis. In one trial, a total mixed ration (TMR) was offered ad libitum whereas in the rest forages were fed ad libitum and concentrates were offered on a flat rate basis with the exception of one treatment within one of the experiments where cows were offered only forage. Grass silage was the main forage component for all diets but in two trials, grass silage was partially replaced with red clover or whole-crop silages. Maize and fresh grass silages were used in two trials and hay was used in four trials. Concentrate supplements contained oats, barley, ground maize, fibrous by-products from the food industry, protein supplements, typically soya bean meal, rapeseed meal or rapeseed expeller and dried or ensiled field pea. All studies used a minimum of one external marker with or without an internal marker. Observed measurements included individual DMI, FDMO, apparent total tract DMD, energy-corrected milk (ECM), body weight (BW), and dietary and faecal marker concentrations. Daily DMls were measured as the difference between feed offered the previous day and refusals in the morning before the first new meal. Measurements of FDMO and DMD for individual cows were made based on total faecal collection in all studies except in studies (62 cow-within period observations) from Denmark where faecal grab samples were used for measurements.

\section{Marker estimations}

Faecal DM outputs were estimated from the concentration of external marker in faeces and the daily dose using the following formula:

$$
\operatorname{eFDMO}(\mathrm{kg} / \mathrm{d})=\frac{\text { marker dose }(\mathrm{g} / \mathrm{d})}{\text { faecal marker concentration }(\mathrm{g} / \mathrm{kg} \mathrm{DM})}
$$

Some studies used more than one external marker. Thus, for one observed measurement, there was equal or multiple numbers of estimates. All external markers in all experiments were used for estimating FDMO. As such, the curated number of observations for estimated FDMO (eFDMO) was greater than that observed (924 v. 354). The external markers used for the determination were, large particle-phase marker (Cr-mordanted fibre), small particle-phase marker (Yb) and liquid-phase markers comprising $\mathrm{Cr}$ - and $\mathrm{Co}$ ethylenediaminetetraacetic acid (EDTA) and polyethylene glycol (PEG). Apparent total tract DMD was also estimated (eDMD) from dietary and faecal concentrations of internal markers, using the following formula:

$$
\begin{aligned}
\operatorname{eDMD}(\mathrm{g} / \mathrm{kg} \mathrm{DM})=1000-1000 \\
\quad \times\left(\frac{\text { dietary marker concentration }(\mathrm{g} / \mathrm{kg} \mathrm{DM})}{\text { faecal marker concentration }(\mathrm{g} / \mathrm{kg} \mathrm{DM})}\right)
\end{aligned}
$$

Some studies used more than one internal marker while others (three from Norway and two from Denmark) used none. All internal markers in all experiments were used for estimating eDMD. As such, the curated number of observations for estimated DMD was greater than that observed (409 v. 354). The internal markers used for the determination were indigestible NDF (iNDF) (determined on ash-free basis) 
and acid insoluble ash (AIA). Individual DMls were also estimated by means of the simultaneous use of an internal marker to estimate eDMD and an external marker to estimate eFDMO using the following equation:

$\mathrm{eDMI}=\frac{1000 \times \mathrm{eFDMO}}{1000-\mathrm{eDMD}}$. Just as above, the curated number of observations for estimated DMI (eDMI) was greater than that observed (846 v. 416). Feed efficiency of individual animals were also estimated from both external and internal markers as $\mathrm{eFE}=\mathrm{g}$ ECM $/ \mathrm{kg}$ eDMI.

\section{Statistical analysis}

Variance components of observed and marker-based variables were estimated using the PROC MIXED procedure of SAS (version 9.4; SAS Institute Inc., Cary, NC, USA) with experiment (Exp), diet within experiment (Diet(Exp)), period within experiment (Period(Exp)) and cow within experiment (Cow(Exp)) as random factors. Covariance structure was specified using the TYPE $=$ VC option in the RANDOM statement. From these estimates, repeatability values (Rep) for DMI, FDMO, DMD, eFDMO, eDMD and eDMI were calculated as Rep $=\frac{\sigma_{\text {Cow }}^{2}}{\sigma_{\text {Cow }}^{2}+\sigma_{\text {Residual }}^{2}}$, where $\sigma_{\text {Cow }}^{2}$ and $\sigma_{\text {Residual }}^{2}$ are $\operatorname{Cow}(\operatorname{Exp})$ and residual variances, respectively. For the observed data, repeatability values estimated the correlation between values from consecutive samples on the same cow, on the same diet and within the same period of the same experiment. Mixed regression models (Supplementary Figures $\mathrm{S1}$ to $\mathrm{S6}$ ) of observed against estimated values were developed for each marker separately (experiment was used as a random effect). They showed varying prediction errors, indicating differences among markers. Therefore, for marker estimated variables, the component marker within experiment (Marker(Exp)) was added. Repeatability values for marker-based variables estimated the correlation between values from consecutive samples of the same marker used on the same cow, on the same diet and within the same period of the same experiment. The standard deviation and CV for each factor were calculated as a percentage of the square root of the variance estimate and standard deviation divided by the corresponding mean value of each factor, respectively.

Relationships between observed variables (DMI, DMD, FDMO and FE) and their corresponding marker based estimates (eDMI, eDMD, eFDMO and eFE) were explored, then models for predicting $\mathrm{FE}$ (defined as $\mathrm{g} \mathrm{ECM} / \mathrm{kg} \mathrm{DMI}$ ) were developed by regression analysis within the MIXED procedure of SAS (Littell et al., 2006) as follows:

$$
Y_{i j}=B_{0}+B_{1} X_{1 i j}+b_{0}+b_{1} X_{1 i j}+B_{2} X_{2 i j}+B_{3} X_{3 i j}+e_{i j}
$$

where $Y_{i j}$ is the expected value for the dependent variable $Y$ observed at level of $j$ of the independent variable $X$ in the study $i_{;} B_{0}$ the overall intercept (fixed effect); $b_{0}$ the random effect of study $i$ on the intercept $(i=1, \ldots, 29) ; b i$ the random effect of study $i$ on the regression coefficient of $Y$ on $X_{1}$ in study $i(i=1, \ldots, 29) ; B_{1}, \ldots, B_{3}$ are regression coefficients of $Y$ on $X_{1}, \ldots, X_{3}$ of $Y$ across all studies (fixed effects); $X_{1 i j}, \ldots, X_{3 i j}$. The value $j$ of the continuous variable $X_{1}, \ldots, X_{3}$ in the study $i_{i}$ and $e_{i j}$ the residual error.
The observed $v$. estimated regression models included one independent variable $X_{1}$ and one random statement: a random intercept and slope of $X_{1}$ with SUBJECT $=$ Marker (Exp) using the TYPE $=$ UN (unstructured covariance). To evaluate model accuracy, root mean square prediction error (RMSPE) was calculated as follows: RMSPE = $\sqrt{ }\left[\Sigma(\text { Observed - Estimated })^{2} / n\right]$, where $n$ is the number of pairs of observed and estimated values being compared. The error was expressed as a proportion of the observed mean to give an estimate of the relative prediction error (RPE). The mean square prediction error (MSPE) was decomposed into random error, error due to the deviation of regression slope from unity and error due to overall bias as described by Bibby and Toutenburg (1977). Residual analyses were conducted by regressing residuals (observed-estimated) on estimated values. Observed values were adjusted for random study effect. To make the slope and intercept estimates in the regression orthogonal and hence independent, estimated values were centred. This was done by subtracting the mean of all estimated values from each estimate as described by StPierre (2003). Mean biases were evaluated by the deviation of regression intercepts from zero while the deviation of the slopes of the regression equations from unity was used to determine the presence of linear biases.

In the FE models, number of independent variables varied between two and three. A basal model was first developed using ECM and BW as independent variables, then each of the marker-based estimates (eDMI, eDMD and eFDMO) was added separately to the basal model to assess their influence on FE predictions. The models included 3 random statements: a random intercept and slope of $X_{1}$ with SUBJECT $=$ $\operatorname{Diet}(\operatorname{Exp})$, a random intercept with SUBJECT $=$ Period(Exp) and a random intercept with SUBJECT = Marker(Exp), using the TYPE $=V C$ (variance components) covariance structure for all random statements. These random statements allowed the effects of study, diet, period and marker to be removed from the estimates. The method $=M L$ (maximum likelihood) statement was used in the PROC MIXED model syntax. Only one random independent variable was used to avoid over-parameterised models and improve convergence (St-Pierre, 2001). The models were evaluated on the basis of residual variance ( $\sigma_{\text {Residual) }}^{2}$.

\section{Results}

\section{Data description}

Mean and ranges of marker recoveries and animal production data are shown in Table 1. Energy-corrected milk production displayed large variation across studies ( $C V=$ $20.7 \%$ ) ranging from 15.1 to $40.6 \mathrm{~kg} /$ day. Body weight averaged $609 \mathrm{~kg}$ and covered the ranges (459 to $790 \mathrm{~kg}$ ). Average eDMD (698 $\mathrm{g} / \mathrm{kg} \mathrm{DM}$ ) was lower than observed DMD $(740 \mathrm{~g} / \mathrm{kg} \mathrm{DM})$. The means of observed DMI and FE were $18.5 \mathrm{~kg} /$ day and $1410 \mathrm{~g} \mathrm{ECM} / \mathrm{kg}$ of DMl, respectively. Estimated DMl averaged $17.5 \mathrm{~kg} /$ day and showed greater variation $(\mathrm{CV}=24.9 \%)$ than observed $\mathrm{DMI}(\mathrm{CV}=14.6 \%)$. 
The overall mean of FDMO was $4.9 \mathrm{~kg}$ for total collection and $5.1 \mathrm{~kg}$ for marker-based estimate, respectively. Average recovery rates of markers were $0.86,0.95,0.80,1.01,0.99$ and $0.94 \mathrm{~g} / \mathrm{g}$ for iNDF, AIA, Cr-mordanted fibre, Ytterbium, Co-EDTA and Cr-EDTA, respectively. There was no recovery rate for PEG because it was used in studies where faecal grab samples were used for FDMO measurements.

\section{Variance components}

The variance components for Exp, Diet(Exp), Period(Exp), Cow(Exp) and Residual to separate experimental, dietary, period and individual animal effects for observed and estimated variables are presented in Tables 2 and 3, respectively. In general, variation associated with the effect of Exp was the largest source of variation for all observed variables (Table 2). Except for DMD where Diet(Exp) variation was similar to $\operatorname{Cow}(\operatorname{Exp})$, the variation due to $\operatorname{Cow}(\operatorname{Exp})$ was higher than that due to Diet(Exp) for DMI and FDMO ( $\mathrm{CV}=8.04 \%$ v. $5.12 \%$ and $10.3 \%$ v. $6.74 \%$, respectively). Between-cow variability was higher for FDMO than for DMI and DMD while DMD exhibited the lowest between-cow variation $(\mathrm{CV}=1.69 \%)$. Repeatability values of observed variables were considerably high ( $\operatorname{Rep} \geqslant 0.54$ ).
For estimated variables, Marker(Exp) was included to separate the effect of marker (Table 3). The variation due to experiment was not significant $(P=0.40)$ for eDMD but tended to have an influence on eDMI $(P=0.10)$. As in the case of the observed variables, between-cow variation for eDMD was of lower magnitude than for eDMI and eFDMO (1.39\% v. $9.07 \%$ and $9.14 \%$, respectively). Overall, variation associated with the effect of marker was the largest source for the variables. However, it is worth noting that Marker (Exp) variation was similar to Exp only for eFDMO. Estimated FDMO showed the highest repeatability $(\operatorname{Rep}=0.51)$ value among marker-based estimates while eDMD recorded the lowest value ( $\operatorname{Rep}=0.12)$. Observed variables relatively gave higher repeatability than their corresponding marker-based estimates.

Predictions of faecal dry matter output, apparent total tract dry matter digestibility and dry matter intake using markers The relationship between FDMO and eFDMO for individual external markers are shown in Supplementary Figure S1 (Cr-mordanted fibre), Supplementary Figure S2 (Yb), Supplementary Figure S3 (Co-EDTA) and Supplementary Figure S4 (Cr-EDTA). Cr-mordanted fibre gave the poorest

Table 1 Description of observed and estimated (intake, excretion, apparent total-tract digestibility) measures, milk production and marker recoveries for the dataset derived from 29 digestibility studies in lactating dairy cows

\begin{tabular}{|c|c|c|c|c|c|}
\hline Items & $n$ & Mean & SD & Minimum & Maximum \\
\hline \multicolumn{6}{|l|}{ Intake (kg/day) } \\
\hline Silage DM & 368 & 11.2 & 2.46 & 2.46 & 18.8 \\
\hline Concentrate DM & 368 & 7.8 & 2.12 & 0.00 & 17.3 \\
\hline \multicolumn{6}{|l|}{ Total DMI } \\
\hline Observed DMI & 416 & 18.5 & 2.71 & 11.3 & 25.8 \\
\hline Estimated eDMI ${ }^{1}$ & 841 & 17.5 & 4.35 & 8.47 & 40.7 \\
\hline ECM (kg/day) & 416 & 26.1 & 5.4 & 15.1 & 40.6 \\
\hline $\mathrm{FE}^{2}$ (g ECM/kg DMI) & 416 & 1410 & 198 & 892 & 2023 \\
\hline BW $(k g)$ & 416 & 609 & 65.3 & 459 & 790 \\
\hline \multicolumn{6}{|l|}{ Faecal DM output (kg/day) } \\
\hline $\mathrm{FDMO}^{3}$ & 354 & 4.9 & 1.00 & 2.18 & 8.37 \\
\hline eFDMO 4 & 929 & 5.1 & 1.31 & 2.18 & 11.3 \\
\hline \multicolumn{6}{|c|}{ Apparent DM digestibility (g/kg DM) } \\
\hline $\mathrm{DMD}^{5}$ & 354 & 740 & 33.0 & 643 & 837 \\
\hline $\mathrm{eDMD}^{6}$ & 401 & 698 & 48.4 & 410 & 855 \\
\hline \multicolumn{6}{|l|}{ Marker recoveries $(\mathrm{g} / \mathrm{g})$} \\
\hline \multicolumn{6}{|l|}{ Internal markers } \\
\hline iNDF & 319 & 0.863 & 0.122 & 0.504 & 1.61 \\
\hline AIA & 27 & 0.945 & 0.053 & 0.886 & 1.10 \\
\hline \multicolumn{6}{|l|}{ External markers } \\
\hline Cr-mordanted fibre & 103 & 0.798 & 0.109 & 0.512 & 0.987 \\
\hline $\mathrm{Yb}$ & 346 & 1.01 & 0.154 & 0.644 & 1.49 \\
\hline Co-EDTA & 163 & 0.989 & 0.175 & 0.617 & 1.53 \\
\hline Cr-EDTA & 193 & 0.944 & 0.088 & 0.647 & 1.30 \\
\hline
\end{tabular}

$\mathrm{DMI}=$ dry matter intake; $\mathrm{ECM}=$ energy-corrected milk.

${ }^{1}$ DMI estimated from both external markers (Cr-mordanted fibre, Yb, polyethylene glycol (PEG), Cr-ethylenediaminetetraacetic acid (EDTA) and Co-EDTA) and internal markers (indigestible NDF (iNDF) and acid insoluble ash (AIA))

${ }^{2}$ Feed efficiency (FE) calculated as gram of ECM/kg of dry matter (DM) intake.

${ }^{3}$ Faecal DM output (FDMO) measured by total collection

${ }^{4}$ Faecal DM output estimated (eFDMO) from external markers (Cr-mordanted fibre, Yb, Co-EDTA, Cr-EDTA and PEG).

${ }^{5}$ Observed apparent total tract DM digestibility (DMD).

${ }^{6}$ Apparent total tract DM digestibility estimated (eDMD) from internal markers (iNDF and AIA). 
Digesta marker for feed efficiency prediction

Table 2 Variance component and repeatability estimates of observed dry matter intake (DMI), apparent total tract dry matter digestibility (DMD) and faecal dry matter output (FDMO) developed using the dataset derived from 29 cross-over studies conducted in lactating dairy cows

\begin{tabular}{|c|c|c|c|c|c|c|}
\hline Items & Estimate & SE & $\operatorname{Pr}>Z^{1}$ & $S D^{2}$ & $\mathrm{CV}^{3}$ & $\operatorname{Rep}^{4}$ \\
\hline DMI ((kg/day), $n=416)$ & & & & & & 0.65 \\
\hline Exp & 3.25 & 1.145 & 0.002 & 1.803 & 9.93 & \\
\hline $\operatorname{Diet}(\operatorname{Exp})$ & 0.87 & 0.194 & $<0.0001$ & 0.930 & 5.12 & \\
\hline Period(Exp) & 0.22 & 0.090 & 0.007 & 0.472 & 2.60 & \\
\hline $\operatorname{Cow}(\operatorname{Exp})$ & 2.13 & 0.377 & $<0.0001$ & 1.459 & 8.04 & \\
\hline Residual & 1.17 & 0.130 & $<0.0001$ & 1.079 & 5.94 & \\
\hline FDMO ((kg/day), $n=354)$ & & & & & & 0.62 \\
\hline Exp & 0.42 & 0.157 & 0.004 & 0.647 & 13.2 & \\
\hline $\operatorname{Diet}(\operatorname{Exp})$ & 0.11 & 0.027 & $<0.0001$ & 0.330 & 6.74 & \\
\hline Period(Exp) & 0.06 & 0.017 & 0.001 & 0.235 & 4.80 & \\
\hline Cow(Exp) & 0.25 & 0.048 & $<0.0001$ & 0.502 & 10.3 & \\
\hline Residual & 0.15 & 0.018 & $<0.0001$ & 0.390 & 7.96 & \\
\hline DMD ((g/kg DM), $n=354)$ & & & & & & 0.54 \\
\hline Exp & 520.5 & 183.89 & 0.002 & 22.82 & 3.08 & \\
\hline $\operatorname{Diet}(\operatorname{Exp})$ & 135.7 & 30.82 & $<0.0001$ & 11.65 & 1.57 & \\
\hline Period(Exp) & 103.9 & 24.46 & $<0.0001$ & 10.19 & 1.38 & \\
\hline $\operatorname{Cow}(\operatorname{Exp})$ & 157.6 & 32.83 & $<0.0001$ & 12.55 & 1.69 & \\
\hline Residual & 135.0 & 16.48 & $<0.0001$ & 11.62 & 1.57 & \\
\hline
\end{tabular}

Exp $=$ experiment; Diet $(\operatorname{Exp})=$ diet within experiment; Period $(\operatorname{Exp})=$ period within experiment; $\operatorname{Cow}(\operatorname{Exp})=$ cow within experiment; DM $=$ dry matter

${ }^{1}$ Probability of Z-value.

${ }^{2}$ Calculated as the square root of the variance-component estimate.

${ }^{3}$ Calculated as the percentage of SD divided by the respective mean value of the variable.

${ }^{4}$ Repeatability $=\frac{\sigma_{\text {cow }}^{2}}{\sigma_{\text {Cow }}^{2}+\sigma_{\text {Residual }}^{2}}$ where $\sigma^{2}{ }_{\text {Cow }}$ and $\sigma^{2}$ Residual are Cow $($ Exp) and residual variances, respectively.

prediction ( $\mathrm{RMSPE}=1.63 \mathrm{~kg} /$ day), about three times the error associated with predictions from the fluid-phase (Co-EDTA$0.49 \mathrm{~kg} /$ day and $\mathrm{Cr}$-EDTA-0.53 kg/day) and small particlephase markers (Yb-0.56 kg/day). Moreover, the relationship between DMD and eDMD for individual internal markers are shown in Supplementary Figure S5 (iNDF) and Supplementary Figure S6 (AIA). Indigestible NDF gave a worse prediction $(\mathrm{RMSPE}=51.9 \mathrm{~g} / \mathrm{kg} \mathrm{DM})$ which is four times the error associated with AIA (11.7 g/kg DM). Predictions from all individual markers were associated with errors. It is not the objective of the present meta-analysis to compare markers for performance. Therefore the discussion on individual markers will not be detailed.

All markers were combined to develop regression equations. The relationship between FDMO and eFDMO (for all external markers combined) is shown in Figure 1a. The following linear relationship was developed with the mixed regression model: $F D M O(\mathrm{~kg} /$ day $)=0.74( \pm 0.010) \times \mathrm{eFDMO}$ $+1.12( \pm 0.056)$. The $R^{2}$ was 0.87 and $\mathrm{RMSPE}=0.55 \mathrm{~kg} / \mathrm{day}$ (10.9\% of the observed mean). External markers overpredicted FDMO by $0.22 \mathrm{~kg} /$ day $(4.4 \%)$. The decomposition of MSPE to mean, slope and random error was $16.3 \%$, $36.3 \%$ and $47.6 \%$, respectively. In residual analysis, the mean (intercept $=-0.22 \pm 0.013, P<0.001$ ) and linear (slope $=-0.26 \pm 0.010, P<0.001$ ) biases were clearly significant as shown in Figure 1b. Figure $2 \mathrm{a}$ shows the relationship between DMD and eDMD (for both AIA and iNDF combined). The RMSPE was $47.2 \mathrm{~g} / \mathrm{kg}, 6.4 \%$ of the observed mean. Internal markers underestimated DMD by
$36.8 \mathrm{~g} / \mathrm{kg}$ DMI (5\% of observed mean). Results showed significant mean and linear biases $(P<0.001$, Figure $2 b)$ and the contribution of mean, slope and random error of total MSPE was $61.1 \%, 26.3 \%$ and $12.6 \%$, respectively. The relationship between DMI and eDMI is shown in Figure 3a. The $R^{2}$ was 0.74 and RMSPE $=2.9 \mathrm{~kg} / \mathrm{day}(15.4 \%$ of the observed mean). The simultaneous use of both external and internal markers underestimated DM intake by $8.8 \%$ (Figure $3 b$ ). This mean bias was clearly significant (intercept $=1.69 \pm 0.042, P<0.001$ ). There was also a presence of slope bias (slope $=-0.48 \pm 0.010, P<0.001$ ). The decomposition of MSPE to mean, slope and random error was $33.1 \%, 49.8 \%$ and $17.1 \%$, respectively.

\section{Feed efficiency models}

The relationship between FE and eFE is shown in Figure 4a. The $R^{2}$ was 0.76 and RMSPE $=265 \mathrm{~g} \mathrm{ECM} / \mathrm{kg} \mathrm{DMI}(18.7 \%$ of the observed mean). Results showed significant mean and linear biases $(P<0.001$, Figure $4 b)$ and the contribution of mean, slope and random error of total MSPE was $31.0 \%$, $54.7 \%$ and $14.2 \%$, respectively. In order to assess the utility of digesta markers in measuring FE, FE (g of ECM per kg of DMI) was modelled using different combinations of ECM and BW with marker estimated variables by mixed model regression (Table 4). Energy-corrected milk was positively related to $\mathrm{FE}(P<0.01)$ while increases in BW were linearly associated $(P<0.01)$ with decreases in FE. Both eFDMO and $\mathrm{eDMI}$ were negatively associated with FE and their inclusion in the model resulted in lower residual variance. The best 
Guinguina, Ahvenjärvi, Prestløkken, Lund and Huhtanen

Table 3 Variance component and repeatability estimates of marker estimated (eDMI, eFDMO and eDMD) ${ }^{1}$ variables developed using the dataset derived from 29 cross-over studies conducted in lactating dairy cows

\begin{tabular}{|c|c|c|c|c|c|c|}
\hline Items $^{2}$ & Estimate & SE & $\operatorname{Pr}>Z^{3}$ & $S D^{4}$ & $C V^{5}$ & $\operatorname{Rep}^{6}$ \\
\hline eDMI ((kg/day), $n=846)$ & & & & & & 0.47 \\
\hline Exp & 3.17 & 2.42 & 0.096 & 1.78 & 10.1 & \\
\hline $\operatorname{Diet}(\operatorname{Exp})$ & 1.30 & 0.295 & $<0.01$ & 1.14 & 6.50 & \\
\hline Period(Exp) & 2.18 & 0.444 & $<0.01$ & 1.48 & 8.40 & \\
\hline $\operatorname{Cow}(\operatorname{Exp})$ & 2.54 & 0.469 & $<0.01$ & 1.60 & 9.07 & \\
\hline Marker(Exp) & 7.30 & 1.86 & $<0.01$ & 2.70 & 15.4 & \\
\hline Residual & 2.90 & 0.172 & $<0.01$ & 1.70 & 9.68 & \\
\hline eFDMO ((kg/day), $n=924)$ & & & & & & 0.51 \\
\hline Exp & 0.51 & 0.229 & 0.013 & 0.713 & 14.1 & \\
\hline $\operatorname{Diet}(\operatorname{Exp})$ & 0.11 & 0.023 & $<0.01$ & 0.333 & 6.57 & \\
\hline Period(Exp) & 0.10 & 0.019 & $<0.01$ & 0.308 & 6.08 & \\
\hline Cow(Exp) & 0.21 & 0.036 & $<0.01$ & 0.463 & 9.14 & \\
\hline Marker(Exp) & 0.52 & 0.131 & $<0.01$ & 0.723 & 14.3 & \\
\hline Residual & 0.21 & 0.012 & 0.013 & 0.458 & 9.04 & \\
\hline eDMD ((g/kg DM), $n=409)$ & & & & & & 0.12 \\
\hline Exp & 147 & 574 & 0.399 & 12.1 & 1.73 & \\
\hline $\operatorname{Diet}(\operatorname{Exp})$ & 196 & 69.9 & 0.003 & 14.0 & 2.00 & \\
\hline Period(Exp) & 183 & 64.4 & 0.003 & 13.5 & 1.93 & \\
\hline Cow(Exp) & 94.8 & 50.3 & 0.030 & 9.73 & 1.39 & \\
\hline Marker(Exp) & 1033 & 621 & 0.048 & 32.1 & 4.59 & \\
\hline Residual & 728 & 81.7 & $<0.01$ & 27.0 & 3.85 & \\
\hline
\end{tabular}

${ }^{1} \mathrm{eFDMO}=$ Faecal dry matter (DM) output estimated from external markers (Cr-mordanted fibre, Yb, Co-EDTA), Cr-EDTA and PEG); eDMD = apparent total tract DM digestibility estimated from internal markers (iNDF and AIA). Refer to Table 1 for marker abbreviations; eDMI=DMI estimated from a combination of external and internal markers above.

${ }^{2} \operatorname{Exp}=$ experiment; Diet $(\operatorname{Exp})=$ diet within experiment; Period $(\operatorname{Exp})=$ period within experiment; $\operatorname{Cow}(\operatorname{Exp})=$ cow within experiment; Marker $(\operatorname{Exp})=\operatorname{marker}$ within experiment.

${ }^{3}$ Probability of Z-value.

${ }^{4}$ Calculated as the square root of the variance-component estimate.

${ }^{5}$ Calculated as the percentage of SD divided by the respective mean value of the variable.

${ }^{6}$ Repeatability $=\frac{\sigma_{\text {cow }}^{2}}{\sigma_{\text {Cow }}^{2}+\sigma_{\text {Residual }}^{2}}$ where $\sigma_{\text {Cow }}^{2}$ and $\sigma_{\text {Residual }}^{2}$ are $\operatorname{Cow}(\operatorname{Exp})$ and residual variances, respectively.

model for predicting FE developed from the dataset was FE $(\mathrm{g} / \mathrm{kg})=1179( \pm 54.05)+38.2( \pm 2.05) \times \mathrm{ECM}(\mathrm{kg} /$ day $)-0.64$ $( \pm 0.051) \times B W \quad(\mathrm{~kg})-75.6( \pm 4.39) \times \mathrm{eFDMO} \quad(\mathrm{kg} /$ day $)$. Although eDMD was positively related to $\mathrm{FE}$, its inclusion in the model only showed a tendency $(P=0.05)$ to reduce the residual variance.

\section{Discussion}

It should be noted that these results were derived from confined cows in Nordic European countries. Cows were offered diets based on mainly grass silage with a wide variety of concentrates. However, application of the present results especially of internal markers to grazing cows or cows offered diets based on non-grass silage should take account of the possible effects of geographic location, management, dietary factors and analytical laboratory procedures because they can alter the dietary and faecal internal marker concentrations. For instance, consumption of soil by grazing animals would undoubtedly nullify results from AIA.

\section{Faecal dry matter output}

Measurement of faecal output is among the most critical determinations necessary for the evaluation of the nutritional status of ruminants. Measurement approaches vary from direct methods (total collection) to indirect techniques using external markers. However, problems associated with marker methods result in variation in faecal marker recovery rates. In this dataset, the recovery of $\mathrm{Cr}$ as large particle phase-marker was rather low $(0.80 \mathrm{~g} / \mathrm{g})$ compared to the small particlephase $(\mathrm{Yb}-1.01 \mathrm{~g} / \mathrm{g})$ and liquid-phase markers (Co-EDTA $0.99 \mathrm{~g} / \mathrm{g}$ and $\mathrm{Cr}$-EDTA $-0.94 \mathrm{~g} / \mathrm{g}$ ). This average $\mathrm{Cr}$ recovery is lower than 0.89 reported by Delagarde et al. (2010). In our study, low recovery of $\mathrm{Cr}$ is surprising because $\mathrm{Cr}$-mordanted straw was administered twice daily (12 h apart) following priming dose via the rumen cannula to facilitate rapid equilibration of the marker concentration in the digestive tract. According to Coates and Penning (2000), twice daily dosing of external markers is usually satisfactory and will reduce the diurnal fluctuations in faecal marker concentrations. Delagarde et al. (2010) provided a number of reasons for the incomplete recovery of external markers. In this meta-analysis, the most likely reason for incomplete $\mathrm{Cr}$ recovery is related to laboratory analysis. Blank faeces were routinely used as a matrix but there are other critical steps that may have distorted the analysis (see Holt, 1993).

One problem of liquid-phase external markers is their short retention time in the digestive tract as they cause larger 


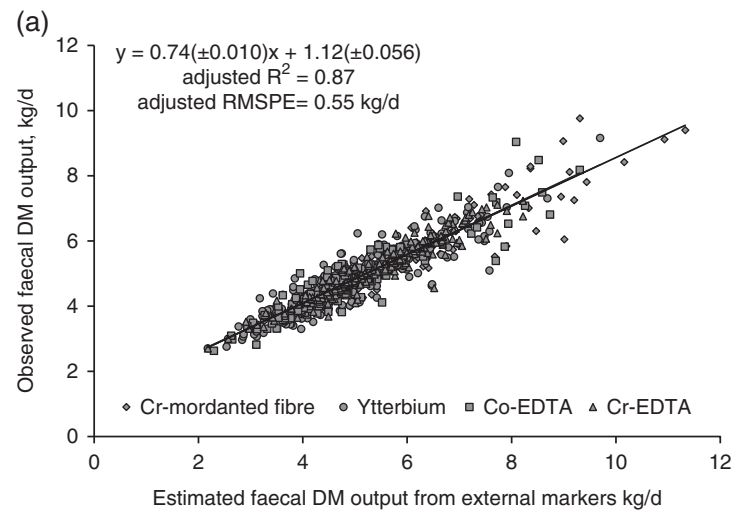

(b)

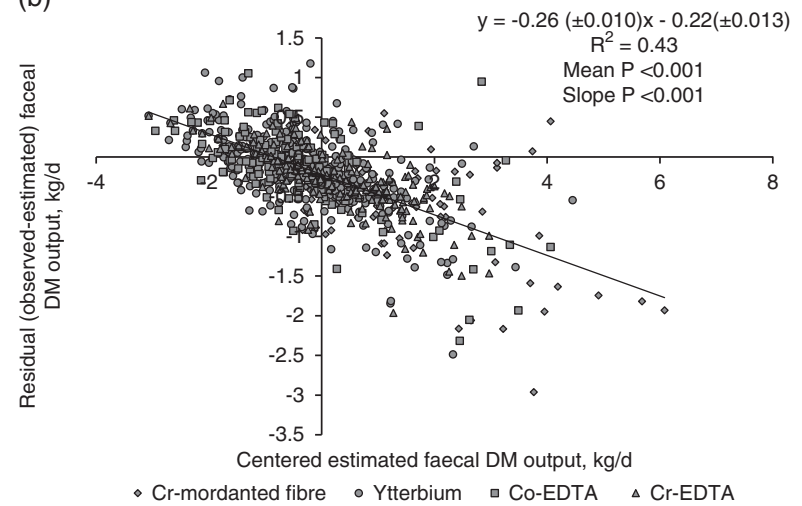

Figure 1 Relationship between estimated and observed faecal dry matter (DM) output $(\mathrm{kg} /$ day) in dairy cows with mixed model regression analysis (a), and between centred estimated values and residuals (observed-estimated) faecal DM output (kg/day), (b), $n=802$. Estimated values were obtained using the external markers, $\mathrm{Cr}$-mordanted fibre, $\mathrm{Yb}$, Co-EDTA and Cr-EDTA (refer to Table 1 for marker abbreviations). $R^{2}$ and root mean square prediction error (RMSPE) are adjusted for random external marker within experiment effect. Estimated values were centred by subtracting the mean of all estimated values from each estimated value.

diurnal variation in marker concentration unless markers are dosed several times in a day (Marais, 2000). In the present meta-analysis, this problem was reduced because of continuous infusion of flow markers ( $\mathrm{Yb}, \mathrm{Cr}$ - and Co-EDTA) following priming doses through the rumen cannula. As such, their mean recovery rates were between 0.94 and $1 \mathrm{~g} / \mathrm{g}$.

The repeatability of FDMO was high for both total collection and marker-based estimate $(0.62$ and 0.57 , respectively). Similarly, the coefficient of determination $\left(R^{2}\right)$ for the prediction of FDMO from eFDMO was high (0.87). However, linear and mean biases were associated with the prediction pointing to the fact that high repeatability and high $R^{2}$ do not always translate to high accuracy. Since the same method (atomic absorption spectroscopy) was used to analyse marker concentrations in feed and faeces across studies, the errors cannot be due to differences in laboratory method. They, however, can be caused by the problems of marker recovery (especially $\mathrm{Cr}$-mordanted fibre) and biases during analytical laboratory procedures. In general, fairly reliable ( $\mathrm{RPE}=10.9 \%$ ) estimates of FDMO can be made using external markers.

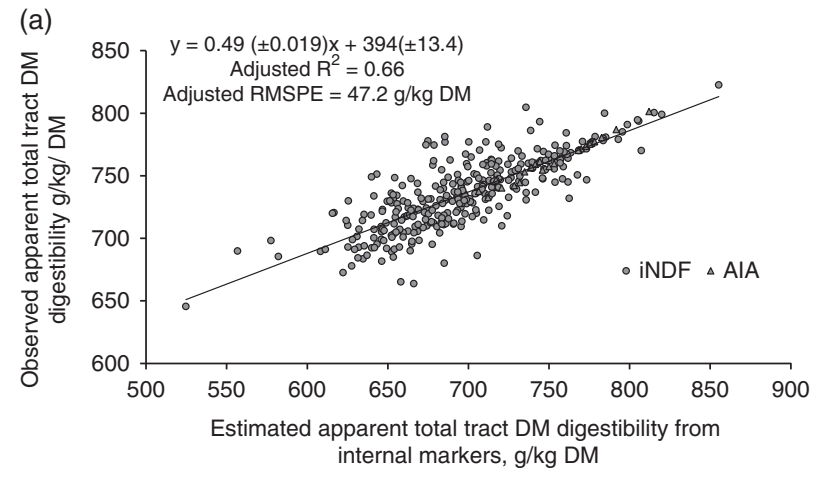

(b)

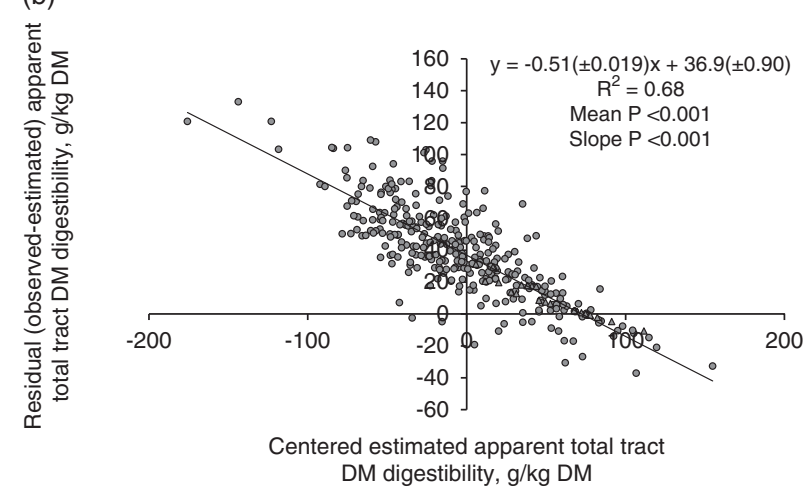

Figure 2 Relationship between estimated and observed apparent total tract dry matter (DM) digestibility ( $/ \mathrm{kg} \mathrm{DM})$ in dairy cows with mixed model regression analysis (a), and between centred estimated values and residuals (observed-estimated) apparent total tract DM digestibility (g/kg DM), (b), $n=346$. Estimated values were obtained using internal markers iNDF and AIA (refer to Table 1 for marker abbreviations). $R^{2}$ and root mean square prediction error (RMSPE) are adjusted for random internal marker within experiment effect. Estimated values were centred by subtracting the mean of all estimated values from each estimated value.

\section{Apparent total tract dry matter digestibility}

Apparent total tract DMD is the single most important measure to describe the nutritive value of diets. Because of existing between-cow variations in DMD, easy methods of determining DMD would be valuable to livestock researchers and producers. The use of internal markers for assessing digestibility is advantageous because the extra step of mixing them into the ration is avoided and if the TMR is mixed correctly, internal markers are well distributed. The betweencow variation in DMD was $1.69 \%(S D=12.6 \mathrm{~g} / \mathrm{kg})$ and this agrees with the $12.3 \mathrm{~g} / \mathrm{kg}$ recorded in earlier studies by Mehtiö et al. (2016) for between-cow variation in organic matter digestibility (OMD) determined using AIA as an internal marker. In our dataset, the eDMD from AIA was associated with a much smaller prediction error (RPE $=$ $1.50 \%$ ). The recovery rate of AIA was also acceptable $(0.95 \mathrm{~g} / \mathrm{g})$. Indigestible NDF, on the other hand, showed higher prediction error $(\mathrm{RPE}=7.0 \%)$ and a lower faecal recovery $(0.86 \mathrm{~g} / \mathrm{g})$. The better performance of AIA than iNDF as a digestibility marker is expected because the cows within experiments were fed mainly grass silage-based diets. Huhtanen et al. (1994) found AIA to be the most suitable digestibility marker for grass silage or hay-based diets 

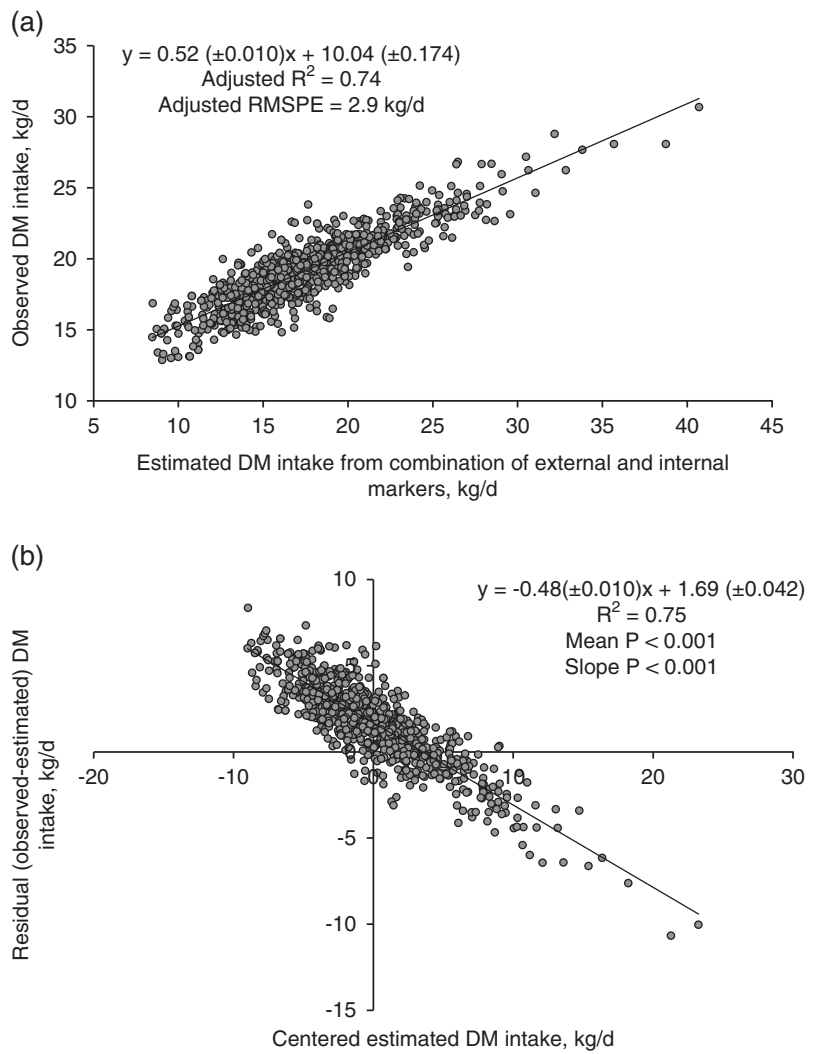

Figure 3 Relationship between estimated and observed dry matter (DM) intake $(\mathrm{kg} /$ day) in dairy cows with mixed model regression analysis (a), and between centred estimated values and residuals (observedestimated) DM intake (kg/day), (b), $n=841$. Estimated values were obtained using the combinations of internal markers (iNDF and AIA) and external markers (Cr-mordanted fibre, Yb, Co-EDTA and $\mathrm{Cr}$-EDTA). Refer to Table 1 for marker abbreviations. $R^{2}$ and root mean square prediction error (RMSPE) are adjusted for random external and internal marker combination within experiment effect. Estimated values were centred by subtracting the mean of all estimated values from each estimated value.

followed by iNDF. Similarly, Nousiainen et al. (2009) found good relationship between observed and estimated OMD based on AIA. In spite of that, low concentrations of AIA may preclude its usefulness as a digestibility marker in maize silage and high grain diets (Lee and Hristov, 2013). Data from Lee and Hristov (2013) showed iNDF to be a more reliable digestibility marker than AIA in dairy cows fed maize silagebased diets. As such, the type of diet should be taken into consideration when estimating DMD using internal markers.

Estimated DMD from both markers were combined to estimate the variance components and the repeatability was rather low (0.12) relative to observed DMD (0.54). The repeatability value is within the range reported by Mehtio et al. (2016) when using iNDF to estimate DMD from NIRS. The relationship between marker-based estimates and observed data showed an under-prediction of DMD by internal markers. A number of reasons could explain the biases especially originating from iNDF. These include analytical method used for estimating iNDF (in vitro $v$. ruminal in situ), different incubation time for ruminal in situ procedures, feed composition, particle grind size, nylon bag pore
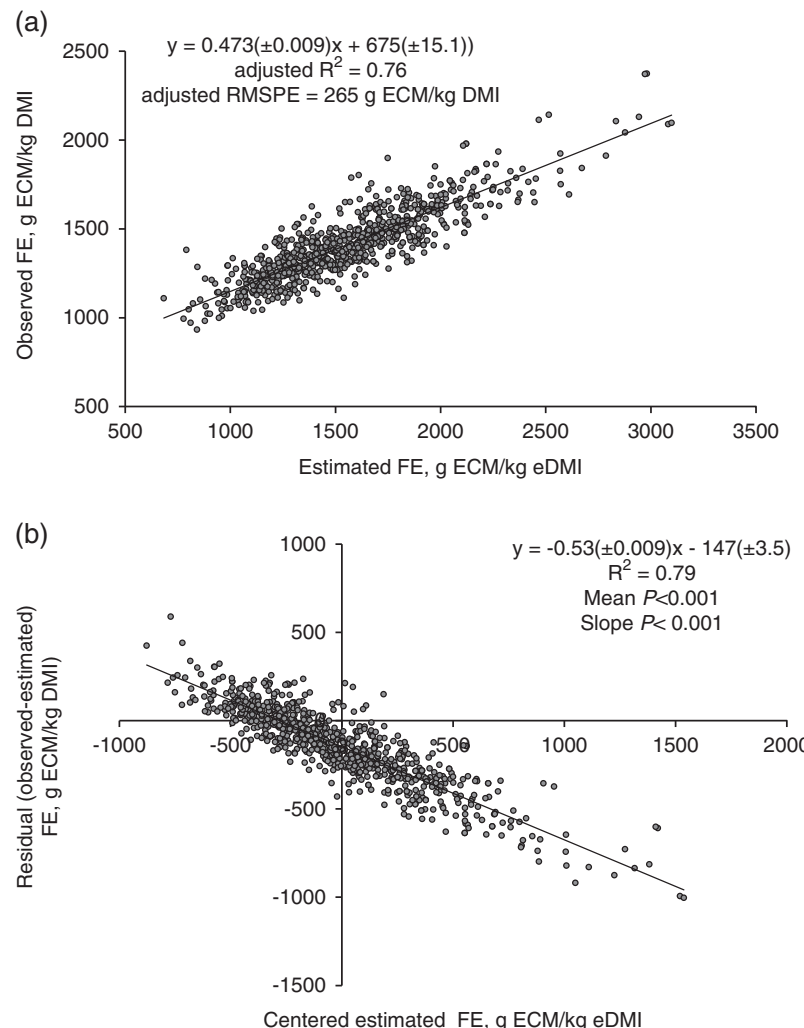

Figure 4 Relationship between estimated and observed feed efficiency $(\mathrm{FE}=\mathrm{kg} \mathrm{ECM} / \mathrm{kg} \mathrm{DMI})$ in dairy cows with mixed model regression analysis (a), and between centred estimated values and residuals (observed-estimated) FE (b), $n=816 . \quad E C M=$ energy-corrected milk; $\mathrm{DMI}=$ dry matter intake. Estimated values of DMI were obtained using the combinations of internal markers (iNDF and AIA) and external markers (Cr-mordanted fibre, Yb, Co-EDTA and Cr-EDTA). Refer to Table 1 for marker abbreviations. $R^{2}$ and root mean square prediction error (RMSPE) are adjusted for random external and internal marker combination within experiment effect. Estimated values were centred by subtracting the mean of all estimated values from each estimated value.

size and biases during analytical laboratory procedures (Krizsan and Huhtanen, 2013; Krizsan et al., 2015). In our study, the bias cannot be attributed to incubation time, feed composition or analytical method used since the procedure (ruminal in situ incubation for $288 \mathrm{~h}$ ) and feed composition (forage to concentrate ratio of $60: 40$ ) remained strictly similar across studies. A possible reason could be related to the particle size $(<2.0 \mathrm{~mm})$ and different pore sizes of the nylon bags $(15,17$ and $36 \mu \mathrm{m}$ in Finland, Norway and Denmark, respectively) used. There are consequences for particle losses, especially with faecal samples. Faecal particles are fragile after digestion, and milling can produce fine particles that are more likely to escape from bags than feed particles. Krizsan et al. (2015) recommended a grind size of $2.0 \mathrm{~mm}$ to be used in ruminal in situ determination of iNDF in order to avoid potential errors.

\section{Dry matter intake}

Direct methods for DMI measurements are costly and not applicable on commercial farms. The simultaneous use of external marker for FDMO and internal marker for DMD 
Table 4 Mixed regression equations developed for predicting feed efficiency $\left(F E=A+B X_{1}+C X_{2}+D X_{3}\right)$ from $E C M, B W$ and marker estimated variables using dataset derived from 29 digestibility studies in lactating dairy cows

\begin{tabular}{lcccccccccrrr}
\hline \hline$X_{1}$ & $X_{2}$ & $X_{3}$ & $n$ & $A^{* *}$ & SE & $B^{* *}$ & SE & $C^{* *}$ & SE & $D^{* *}$ & SE & $\sigma^{2}{ }_{\text {Residual }}$ \\
\hline ECM & BW & & 416 & 1053 & 67.3 & 27.9 & 1.61 & -0.60 & 0.095 & & 11400 \\
ECM & BW & eFDMO & 872 & 1179 & 54.1 & 38.2 & 2.05 & -0.60 & 0.051 & -75.6 & 4.39 \\
ECM & BW & eDMD & 387 & 749 & 126 & 27.3 & 1.60 & -0.48 & 0.098 & $0.32 *$ & 0.158 & 10934 \\
ECM & BW & eDMl & 816 & 1095 & 70.7 & 36.3 & 2.77 & -0.59 & 0.054 & -16.3 & 1.20 & 4847 \\
\hline \hline
\end{tabular}

$\mathrm{ECM}=$ energy-corrected milk; $\mathrm{BW}=$ Body weight; eFDMO = faecal dry matter (DM) output estimated from external markers (Cr-mordanted fibre, Yb, Coethylenediaminetetraacetic acid (EDTA) and (r-EDTA); eDMD = apparent total tract DM digestibility estimated from internal markers (iNDF and AIA); eDMI = DM intake estimated from a combination of external (Cr-mordanted fibre, Yb, Co-EDTA, Cr-EDTA) and internal markers (iNDF and AIA). Refer to Table 1 for marker abbreviations; $\sigma 2{ }_{\text {Residual }}=$ residual variance.

${ }^{*} P=0.05 ;{ }^{* *}$ all $P$-values $\leqslant 0.01$.

estimates has been employed for indirect measurement of DMI (Ferret et al., 1999; Ahvenjärvi et al. 2018). In our study, several combinations of external and internal markers were used for DMI estimates. Repeatability estimates of DMI in different populations are lacking, but estimates in the present study ( 0.65 for $\mathrm{DMI}$ and 0.47 for eDMI) are consistent with the across lactation repeatability of 0.66 documented by Berry et al. (2014) from individual daily feed intake of Holstein-Friesian cows and heifers from nine countries. The high repeatability of eDMI indicates its potential to be used in estimating DMI for correct ranking of cows aimed at selection purposes.

Despite the high repeatability of eDMl, its prediction of observed DMI showed both mean and slope biases. In a recent study, Ahvenjärvi et al. (2018) estimated eDMI from a combination of iNDF and PEG. In that study, using the same eDMD for a group of cows fed the same diet resulted in more accurate DMI prediction than using animal-specific eDMD. The authors established that to improve DMI predictions, cow-specific eDMD must be determined with high precision and accuracy over those based on group-specific eDMD. Inherently, the biases in predicting DMI in our study could be attributed to the problems enumerated above for DMD as well as FDMO estimates. Markers underestimated DMI at low measured feed intake and overestimated DMI at high measured DMI. Generally, our model under-predicted DMI with an $\mathrm{RPE}=15.4 \%$. According to Fuentes-Pila et al. (1996), an RPE lower than 10\% indicated a satisfactory prediction of DMl; RPE between 10\% and $20 \%$ indicated relatively good or acceptable predictions, and RPE greater than $20 \%$ indicated unsatisfactory predictions. Even though the prediction may be inaccurate, it is precise (high $R^{2}$ and repeatability) and provides acceptable estimates of DMI. However, recognition of the inadequacies involved and caution is necessary for interpretation of data.

\section{Feed efficiency models}

Several measures exist for FE but no single measure can be applicable to all farms. Dry matter intake is a key component of all FE measures. However, the high cost of DMI measurements in large herds has limited its recording to only research herds. In the current study, the indirect method of estimating intake from digesta markers was used. Subsequently, the estimated DMI was used to estimate FE (eFE) in its simplest form, feed conversion efficiency (FCE) expressed as the ratio of ECM to DMI (Linn, 2006). Marker-based estimate of FE (eFE) precisely (high $R^{2}$ ) predicted observed FE but was inaccurate due to the presence of both mean and slope biases. Although FCE is easy to measure and conceptually simple, it has been criticised for not estimating the metabolic efficiency of animals and for possible negative consequences it has on traits including energy balance, health and fertility (Connor, 2015). One way to improve FCE measurement is to use a basal linear model with milk production and BW (mainly to account for the metabolic efficiency) as independent variables because they can easily be measured on-farm. They are also, known to greatly influence FE as they are important drivers of feed intake (VandeHaar, 2016). Furthermore, expressing $\mathrm{FE}$ as $\mathrm{ECM} / \mathrm{eDMl}$ still requires the use of both internal and external markers which necessitates higher analytical cost and intensive labour. Since the goal is to find simple, low cost but accurate and precise analytical techniques, we added each of the marker-based estimates to the basal model so as to assess the effectiveness of using single markers (either internal markers for eDMD or external markers for eFDMO) and double markers (combination of both internal and external markers for eDMI) in FE measurements.

In our study, ECM was positively associated with FE. At constant BW, $1 \mathrm{~kg}$ increase in ECM resulted in an increase of $27.9 \mathrm{~g} / \mathrm{kg}$ in FE. Spurlock et al. (2012) also reported a strong positive correlation $(r=0.87)$ between FCE and milk yield. This implies that as milk yield increases among dairy herds, corresponding gains in FCE would be achieved. Selecting for FCE a trait based on the ratio of two component traits, however, can produce unpredictable results if done in early lactation. In early lactation, greater milk output increases the cow's energy requirement which cannot be met solely by increased feed intake causing mobilisation of energy from her body tissue to support the increased energy demand for lactation (Connor, 2015). This occurrence contributes to strong negative genetic correlations between FCE and body condition score (BCS) and energy balance (Vallimont et al., 2011; Spurlock et al., 2012). Hence, improvements in FCE will lead to a simultaneous selection of cows that exhibit negative energy balance and lower BCS during early lactation. Greater losses in BCS and energy balance are linked with poor fertility performance and health (Roche et al., 2007). The study of Spurlock et al. (2012) further showed no correlation between FCE and energy 
balance when the evaluation was made in mid-lactation (75 to 150 days in milk). This suggests a possibility to select for improved FCE specifically during this period with a lower risk of metabolic imbalance (Hooven et al., 1972). The cows used for this study were in mid-lactation.

Feed conversion efficiency is also strongly and negatively correlated ( $r=-0.66$ ) with BW (Vallimont et al., 2011). In our study, the relationship between $\mathrm{FE}$ and $\mathrm{BW}$ was negative. One kilogram gain in BW resulted in $0.60 \mathrm{~g} / \mathrm{kg}$ loss in FE. Linn et al. (2009) reported that animals of high BW $(815 \mathrm{~kg})$ had lower FE (1320 v. $1550 \mathrm{~g} / \mathrm{kg})$ on average compared with animals of low BW $(545 \mathrm{~kg})$. These findings demonstrate that heavy cows are less efficient than light cows. Freeman (1975) stated that heavier weight is undesirable especially when it is negatively correlated with efficiency both phenotypically and genetically. This difference is likely the result of the greater requirement for maintenance as $\mathrm{BW}$ is one of the factors closely related to net energy for maintenance (Searle et al., 1982). A bigger (or heavier weight) animal will partition more energy for maintenance and less to production than a smaller animal would at the same feeding level. Thus, one way to improve $\mathrm{FE}$ is to decrease maintenance requirement by selecting for cows that are smaller where significant gains in FE can be captured by extra dilution of maintenance. Furthermore, the use of BW alone in estimating maintenance requirement could be misleading due to variation in BCS. The degree of error that can occur in the calculation of maintenance requirements if the $\mathrm{BCS}$ of the cow is not taken into account is emphasised in the study of Birnie et al. (2000). In the present studies, the BCS of cows was not taken into account in predicting FE because it was not measured. Moreover, measurements were made in mid-lactation, a period of minimal to no losses in BCS.

In our studies, a combination of both internal and external markers was used to estimate DMI. Despite the inaccuracy of both markers in estimating DMI, they were useful in predicting $\mathrm{FE}$. Accounting for eDMI in the FE model reduced the residual variance by $57.5 \%$. Marker estimated DMI was negatively related to FE. When BW and ECM are kept constant, $1 \mathrm{~kg}$ of DM consumed resulted in $16.3 \mathrm{~g} / \mathrm{kg}$ reduction in $\mathrm{FE}$. A field study of six commercial herds by Casper et al. (2004) also demonstrated an inverse relationship between FE and DMI. This indicates that cows with lower DMI have the ability to use less dietary energy to achieve higher levels of milk production as a result of maximised digestibility (Varga et al., 2013).

The digestibility of the diet reduces as the ingestion of total DM is elevated, essentially due to increased cell wall passage rate and decreased ruminal retention time (Huhtanen et al., 2009). Gabel et al. (2003) observed that lactating cows fed the same diet, but at 1.4, 2.7 and 4.6 times their energy requirements for maintenance, showed a decrease in $\operatorname{DMD}(74.8 \%, 72.3 \%$ and $67.2 \%$, respectively) only with an increase in dietary DMI. Similarly, other authors reported linear depression in digestibility with increased intake (Colucci et al., 1989; Huhtanen et al., 2009). Since DMI is the denominator of $\mathrm{FE}$, a negative relationship between $\mathrm{DMI}$ and
DMD suggests that increased digestibility would improve FE. For Casper et al. (2004) FE of cows from six dairy farms fed TMR was positively and significantly related to the eDMD from AIA. In the current study, eDMD was also positively related to FE but only showed a tendency to increase FE. In a larger dataset from production studies, the effect was significant (P. Huhtanen, Swedish University of Agricultural Sciences, Umeå, Sweden, personal communication). In studies, with cannulated cows such as this one, there can be more random variability due to stress caused by excessive interaction between people and animals. The inclusion of eDMD in the FE model only reduced the residual variance by $3.7 \%$. The lack of improvement in the model could be attributed to the low between-cow variation (though significant but small) in eDMD.

The implication from an environmental stance is that improving DMD would reduce FDMO. In this dataset, the relationship between eFDMO and FE was negative and the inclusion of eFDMO in the FE model gave the lowest residual variance. Increased FDMO leads to reduced FE, either as a result of greater DMI and/or reduced digestibility. Limiting DMI reduces the passage rate, which increases residence time in the digestive tract, thereby increasing DMD and lowering FDMO.

The between cow variation was highest for eFDMO amongst all marker estimated variables pointing to the suitability of external markers over internal markers in estimating the between animal differences in FE. In addition, using eDMD to predict DMI is sensitive to even small errors in DMD. For example, $\pm 3 \%$ unit differences in DMD at $700 \mathrm{~g} / \mathrm{kg}$ DMD represent about $10 \%$ errors in DMI and FE. Considering possible inaccuracies, labour intensiveness and analytical costs of the marker techniques, a more practical option to acquire reliable FE data for genetic evaluation in the future is to estimate only FDMO by external markers for FE models.

\section{Conclusion}

The present analysis showed higher repeatability for observed measurements than marker-based estimates. This suggests that direct measurement of FDMO, apparent total tract DMD and DMI is the method of choice particularly in confinement systems unless otherwise impossible due to facility limitations. Marker-based estimate of FDMO explained most of the variability in FE pointing to the potential of ranking cows for FE based on FDMO estimated from external markers. Measuring DMD with internal markers did not improve prediction of $\mathrm{FE}$ reflecting small between cow variation in DMD and random errors associated with measurements.

\section{Acknowledgements}

The authors gratefully acknowledge the contributions of colleagues from Agri-Food Research in Finland (currently Natural 
Resources Institute Finland-LUKE, Jokioinen, Finland), Aarhus University (Aarhus, Denmark) and Norwegian University of Life Sciences (Ås, Norway), for providing the data to complete the individual cow dataset. This study was supported financially by the Feed Utilisation in Nordic Cattle (FUNC) project.

\section{Declaration of interest}

The authors declare no conflicts of interest.

\section{Ethics statement}

The experiments contributing to the present meta-analysis complied with the guidelines of the respective national legislations on animal experimentation and care of animals under study.

\section{Software and data repository resources}

None of the data were deposited in an official repository.

\section{Supplementary material}

To view supplementary material for this article, please visit https://doi.org/10.1017/S1751731119000247

\section{References}

Ahvenjärvi S, Nyholm L, Nousiainen J, Mäntysaari E and Lidauer M 2018. Polyethylene glycol as an indigestible marker to estimate fecal output in dairy cows. Journal of Dairy Science 101, 4245-4258.

Berry DP, Coffey M, Pryce J, De Haas Y, Løvendahl P, Krattenmacher N, Crowley J, Wang Z, Spurlock D and Weigel K 2014. International genetic evaluations for feed intake in dairy cattle through the collation of data from multiple sources. Journal of Dairy Science 97, 3894-3905.

Bibby J and Toutenburg H 1977. Prediction and improved estimation in linear models. John Wiley \& Sons, London, UK.

Birnie J, Agnew R and Gordon F 2000. The influence of body condition on the fasting energy metabolism of nonpregnant, nonlactating dairy cows. Journal of Dairy Science 83, 1217-1223.

Casper D, Whitlock L, Schauff D, Jones D, Spangler D and Ayangbile G 2004 Feed efficiency is driven by dry matter digestibility. Journal of Dairy Science 87 (suppl. 1), 462.

Coates D and Penning P 2000. Measuring animal performance. In Field and laboratory methods for grassland and animal production research (ed. L ' $t$ Mannetje and RM Jones), pp. 353-402, CAB International, Wallingford, UK.

Coleman SW 2005. Predicting forage intake by grazing ruminants. In Proceedings of 16th ruminant nutrition symposium, 1-2 February 2005, Gainesville, FL, USA, pp. 72-90.

Colucci P, Macleod G, Grovum W, Cahill L and McMillan I 1989. Comparative digestion in sheep and cattle fed different forage to concentrate ratios at high and low intakes. Journal of Dairy Science 72, 1774-1785.

Connor E 2015. Invited review: Improving feed efficiency in dairy production: challenges and possibilities. Animal 9, 395-408.

Delagarde R, Pérez-Ramírez E and Peyraud JL 2010. Ytterbium oxide has the same accuracy as chromic oxide for estimating variations of faecal dry matter output in dairy cows fed a total mixed ration at two feeding levels. Animal Feed Science and Technology 161, 121-131.

Ferret A, Plaixats J, Caja G, Gasa J and Prio P 1999. Using markers to estimate apparent dry matter digestibility, faecal output and dry matter intake in dairy ewes fed Italian ryegrass hay or alfalfa hay. Small Ruminant Research 33, 145-152.

Freeman A 1975. Genetic variation in nutrition of dairy cattle. In Proceedings of the effect of genetic variance on nutritional requirements of Animals symposium, 31 July 1974, Maryland, MD, USA, pp. 19-46.

Fuentes-Pila J, DeLorenzo M, Beede D, Staples C and Holter J 1996. Evaluation of equations based on animal factors to predict intake of lactating Holstein cows1. Journal of Dairy Science 79, 1562-1571.
Gabel M, Pieper B, Friedel K, Radke M, Hagemann A, Voigt J and Kuhla S 2003. Influence of nutrition level on digestibility in high yielding cows and effects on energy evaluation systems. Journal of Dairy Science 86, 3992-3998.

Holt N 1993. Calibration curves for the determination of low levels of chromium in feces. Canadian Journal of Animal Science 73, 109-115.

Hooven N, Miller R and Smith J 1972. Relationships among whole-and partlactation gross feed efficiency, feed consumption, and milk yield. Journal of Dairy Science 55, 1113-1122.

Huhtanen P, Kaustell K and Jaakkola S 1994. The use of internal markers to predict total digestibility and duodenal flow of nutrients in cattle given six different diets. Animal Feed Science and Technology 48, 211-227.

Huhtanen P, Rinne M and Nousiainen J 2009. A meta-analysis of feed digestion in dairy cows. 2. The effects of feeding level and diet composition on digestibility. Journal of Dairy Science 92, 5031-5042.

Krizsan SJ and Huhtanen P 2013. Effect of diet composition and incubation time on feed indigestible neutral detergent fiber concentration in dairy cows. Journal of Dairy Science 96, 1715-1726.

Krizsan SJ, Rinne M, Nyholm L and Huhtanen P 2015. New recommendations for the ruminal in situ determination of indigestible neutral detergent fibre. Animal Feed Science and Technology 205, 31-41.

Lee $C$ and Hristov A 2013. Evaluation of acid-insoluble ash and indigestible neutral detergent fiber as total-tract digestibility markers in dairy cows fed corn silage-based diets. Journal of Dairy Science 96, 5295-5299.

Linn J 2006. Feed efficiency: its economic impact in lactating dairy cows. WCDS Advances in Dairy Technology 18, 19-28.

Linn J, Raeth-Knight M and Litherland N 2009. Role of feed (dairy) efficiency in dairy management. In Proceedings of the 44th Pacific Northwest Animal Nutrition Conference, October 2009, Boise, ID, USA, pp. 167-176.

Littell RC, Milliken GA, Stroup WW, Wolfinger RD and Schabenberger 02006. SAS for Mixed Models, 2nd edition. Statistical Analysis Systems Institute Inc., Cary, NC, USA.

Marais J 2000. Use of markers. In Farm animal metabolism and nutrition: critical reviews (ed. JPF D'Mello), pp. 255-277. CAB International, Wallingford, UK.

Mehtiö T, Rinne M, Nyholm L, Mäntysaari P, Sairanen A, Mäntysaari E, Pitkänen T and Lidauer M 2016. Cow-specific diet digestibility predictions based on nearinfrared reflectance spectroscopy scans of faecal samples. Journal of Animal Breeding and Genetics 133, 115-125.

Moore J 1996. Practical approaches to estimating pasture intake. In Proceedings of Nutrient Cycling in Forage Systems Symposium, 7-8 March 1996, Columbia, MO, USA, $193 \mathrm{pp}$

Nousiainen J, Rinne M and Huhtanen P 2009. A meta-analysis of feed digestion in dairy cows. 1. The effects of forage and concentrate factors on total diet digestibility. Journal of Dairy Science 92, 5019-5030.

Pryce JE, Gonzalez-Recio 0, Nieuwhof G, Wales WJ, Coffey MP, Hayes BJ and Goddard ME 2015. Hot topic: definition and implementation of a breeding value for feed efficiency in dairy cows. Journal of Dairy Science 98, 7340-7350.

Roche J, Macdonald K, Burke C, Lee J and Berry D 2007. Associations among body condition score, body weight, and reproductive performance in seasonalcalving dairy cattle. Journal of Dairy Science 90, 376-391.

Sales J and Janssens $G$ 2003. Acid-insoluble ash as a marker in digestibility studies: a review. Journal of Animal and Feed Sciences 12, 383-400.

Searle T, Graham N M and Donnelly J 1982. The effect of plane of nutrition on the body composition of two breeds of wearier sheep fed a high protein diet. The Journal of Agricultural Science 98, 241-245.

Spurlock D, Dekkers J, Fernando R, Koltes D and Wolc A 2012. Genetic parameters for energy balance, feed efficiency, and related traits in Holstein cattle. Journal of Dairy Science 95, 5393-5402.

St-Pierre NR 2001. Invited review: Integrating quantitative findings from multiple studies using mixed model methodology. Journal of Dairy Science 84, 741-755.

St-Pierre NR 2003. Reassessment of biases in predicted nitrogen flows to the duodenum by NRC 2001. Journal of Dairy Science 86, 344-350.

Tempelman RJ, Spurlock DM, Coffey M, Veerkamp RF, Armentano LE, Weigel $K A$, de Haas Y, Staples CR, Connor EE, Lu Y and VandeHaar MJ 2015. Heterogeneity in genetic and nongenetic variation and energy sink relationships for 
Guinguina, Ahvenjärvi, Prestløkken, Lund and Huhtanen

residual feed intake across research stations and countries. Journal of Dairy Science 98, 2013-2026.

Vallimont J, Dechow C, Daubert J, Dekleva M, Blum J, Barlieb C, Liu W, Varga G, Heinrichs $A$ and Baumrucker C 2011. Short communication: Heritability of gross feed efficiency and associations with yield, intake, residual intake, body weight, and body condition score in 11 commercial Pennsylvania tie stalls. Journal of Dairy Science 94, 2108-2113.
VandeHaar MJ 2016. Understanding the physiological aspects to improving feed efficiency in dairy cows. In Tri-State Dairy Nutrition Conference, 18-20 April 2016, Fort Wayne, IN, USA, 25th Anniversary, pp. 27-34.

Varga G, Dechow C and Eastridge M 2013. Can we use residual feed intake to enhance dairy production efficiency? In Proceedings of the 22nd TriState Dairy Nutrition Conference, Fort Wayne, IN, USA, 23-24 April 2013, pp. 131-140. 